\title{
UNEXPECTED EFFECTS OF HISTORIC CONCRETE INNOVATIONS
}

\author{
RENE BRUECKNER \& PAUL LAMBERT \\ Materials and Corrosion Engineering, Mott MacDonald, UK
}

\begin{abstract}
Concrete, as a building material, dates back to at least seven millennia. Its earliest evidence was found on the Balkan Peninsula but since then it has undergone continuous development. It became more widely used since $3000 \mathrm{BC}$ with probably the most famous concrete structure from ancient times being the Pantheon in Rome which was built in $120 \mathrm{AD}$ using pozzolanic concrete. The next significant step in the development of concrete was not before the beginning of the 19th century when Portland cement was first patented.

Portland cement-based concrete has undergone many modifications based on field experience and extensive research to enhance the performance of the resultant concrete, not always successfully. To reduce construction time, calcium chloride has been used as a set accelerator since 1873 . This admixture has since contributed to significant damage due to chloride-induced corrosion of embedded reinforcement. Concretes based on other binders also appeared, such as high alumina cement (HAC), but is now banned for structural use in many countries due to a number of high-profile failures. Mortar based on Portland cement has also been used as repair material without considering its incompatibility, for example, with gypsum mortars.

This article will discuss a number of once state-of-the-art building materials that may still be encountered in the renovation of heritage structures, and the methods and precautions required when carrying out their remediation.

Keywords: asbestos, building codes, calcium chloride, cement, concrete, corrosion, high alumina, historic innovations.
\end{abstract}

\section{INTRODUCTION}

Building materials have appeared, developed and been replaced by innovations throughout millennia. The earliest development of concrete as a building material can be dated back to between $6500 \mathrm{BC}$ and $5600 \mathrm{BC}$ [1, 2]. Concrete is a stone-like material which consists of a mixture of aggregate (sand, gravel, crushed rock), water and a binding material that hardens as a result of chemical reactions of the binder and water with or without carbon dioxide. Modern binders are mainly cementitious whereas historic binders can be based on lime or pozzolanic materials.

In the Middle East, the Nabataea constructed the first concrete-like structures around $6500 \mathrm{BC}$ due to the accidental discovery of lime of a binding material [1]. Up until $700 \mathrm{BC}$ they developed their technique so that hydraulic lime could be produced in kilns to construct rubble-wall houses, floors and underground waterproof cisterns [1]. At the Lepenski Vir settlement in Serbia on the Balkan Peninsula a 250-mm-thick hut floor was discovered that dates back to $5600 \mathrm{BC}$ [2]. The floor consisted of a mixture of stone, gravel and lime. More widespread and considered use is recorded from 3000 BC onwards [3]. In Egypt a mud consisting of lime and gypsum was employed which also contained straw as reinforcement [3]. The Assyrians and Babylonians used clay as a bonding substance [3]. In China a 'cementitious' material containing bamboo was used to construct the Great Wall. This type of mortar consisted of rice flour and slaked lime, a common mortar component [4]. 


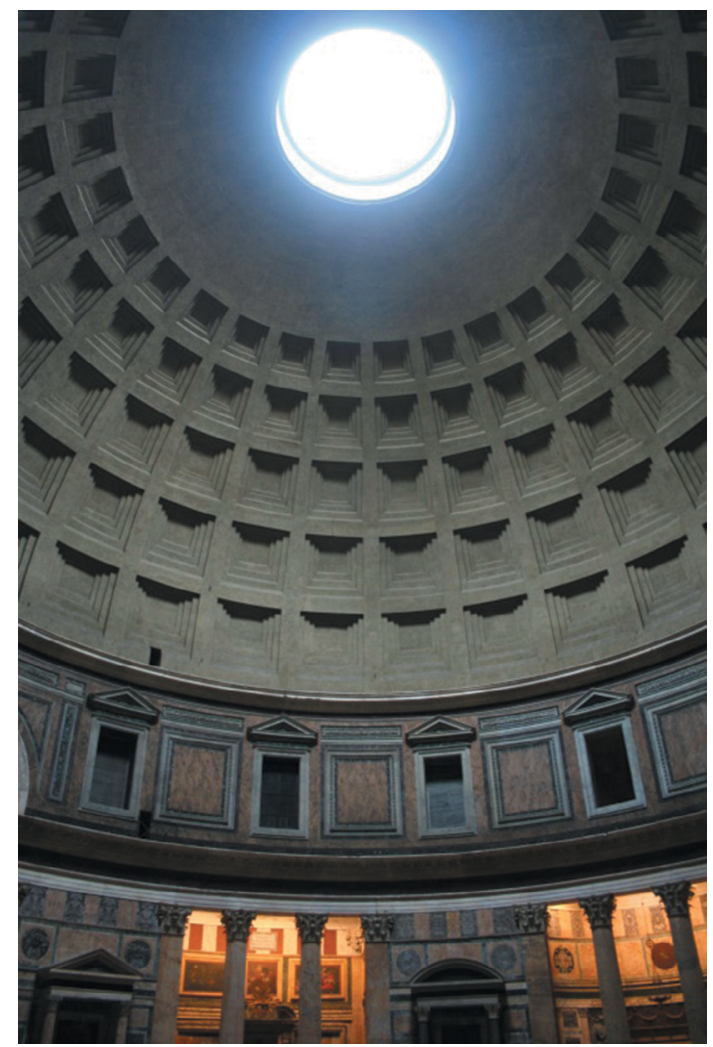

Figure 1: Pantheon, Rome.

Probably the most famous concrete structure from ancient times is the Pantheon in Rome which was built between 118 and 125 AD (see Fig. 1). During the time of the Roman Empire, concrete had undergone various significant developments. From 300 BC Romans used a mixture of slaked lime and volcanic ash from Pozzuoli, a small town close to the Vesuvius. The addition of lime to the ash initiated a complex hydration reaction to form calcium-silicatehydrates $(\mathrm{CSH})$ and the first pozzolanic material. The modern words associated to concrete derived from Roman nomenclature in Latin where 'caementum' means rough stone or chipping and 'concretus' grown together or compounded. The term 'pozzolana' derives from the place Pozzuoli where a source of pink volcanic ash was discovered to react with lime-based mortars to form a durable material that was used in the construction of the Harbour in Pozzuoli. Pozzolana is 'a siliceous or siliceous and aluminous material which, in itself, possesses little or no cementitious value but which will, in finely divided form in the presence of moisture, react chemically with calcium hydroxide at ordinary temperature to form compounds possessing cementitious properties' [5].

After the fall of the Roman Empire the formulation of such advanced concretes was lost for more than a millennium until the 18th century, defined by John Smeaton's development of a hydraulic lime-pozzolan mortar for use in the construction of the Eddystone Lighthouse off the south-west coast of England (Fig. 2). The rise of modern Western civilizations, beginning with the great migrations to North America and the subsequent industrialization, required the development of stronger, durable and more readily available building materials. The existing 


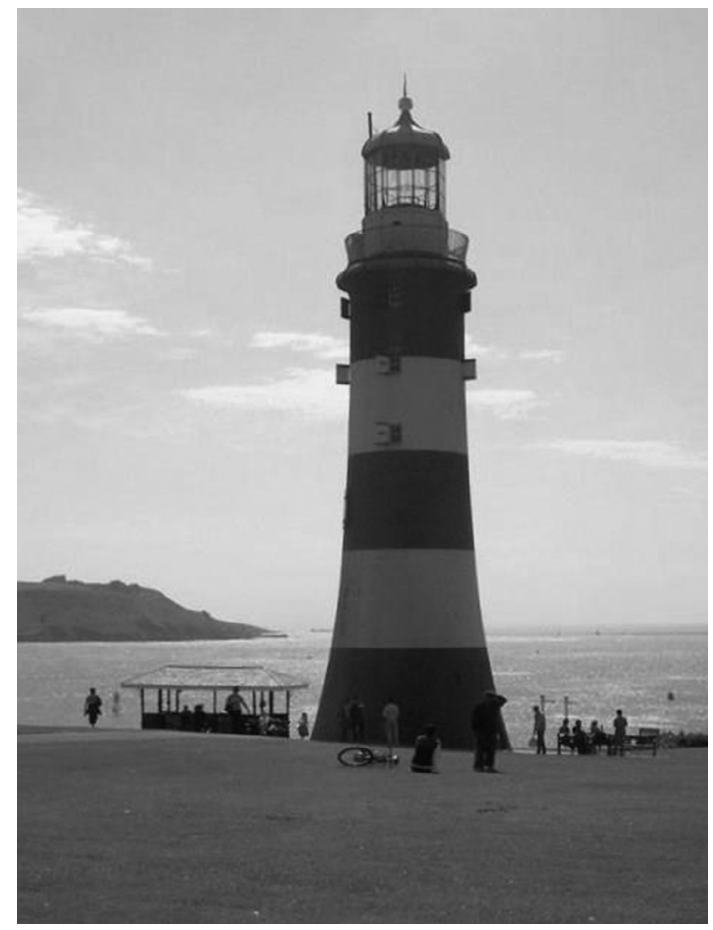

Figure 2: Smeaton's Eddystone Lighthouse, completed 1759, relocated 1877 (photo: Lewis Clark).

brick, stone and timber construction methods were sufficient until the demand rose for even faster methods to realize much grander dreams and ideas.

The Bridgewater Canal in the North West of England was built to transport coal to the industrial areas of Manchester with its first section opened in 1761. It was the first canal in Britain that was built without following an existing watercourse. Its extraordinary success led to widespread improvements in the transport system of Britain and later in the British colonies of North America. The challenges imposed during the planning and construction of the 584-km Erie Canal from 1817 until 1825 required the development of a plentiful and rapidly constructed watertight material. Canvas White discovered the existence of a natural lime-based cement with hydraulic properties in Chittenango, New York, that would provide the required watertight mortar [6]. Modern concrete was born when Joseph Aspdin, a Leeds bricklayer, patented Portland cement in 1824. He created the first mass-produced and widely accepted artificial cement by burning ground limestone and clay together. The basic recipe of Portland cement has remained largely unchanged until the present day and forms the basis of most concrete and hydraulic mortar.

Reinforced concrete as it is known today appeared in the late 1840s when Joseph-Louis Lambot built the oldest known boat using ferrocement in 1848 which featured in the Exposition Universelle in Paris in 1855 [7]. At the same time Joseph Monier, a gardener from Paris, reinforced garden pots with an iron mesh and later promoted the use of reinforced concrete for pipes, floors, arches and bridges. Reinforced concrete was however not patented until 1867 [8]. 
Other types of binders were developed at the beginning of the 20th century that have been used in the construction of concrete structures, usually with only limited success. This may have been due to the dominance and reliability of Portland cement concrete and the problems in its use that were often encountered.

\section{BUILDING CODES}

Simultaneously with the development of the construction methods and materials, building codes have appeared throughout the ages because the integrity and durability of structures has been an important requirement throughout civilization. The first recorded rules for builders were introduced by King Hammurabi in Babylon around $1700 \mathrm{BC}$ and did not change greatly until the Middle Ages in Europe. The code of Hammurabi [9] consists of 282 laws dealing with contracts, household and family matters and one part discusses transactions which includes the liability of a builder as stated in paragraphs 228-231:

- Paragraph 228. If a builder has built a house for a man, and finished it, he shall pay him a fee of two shekels of silver, for each SAR built on.

- Paragraph 229. If a builder has built a house for a man, and has not made his work sound, and the house he built has fallen, and caused the death of its owner, that builder shall be put to death.

- Paragraph 230. If it is the owner's son that is killed, the builder's son shall be put to death.

- Paragraph 231. If it is the slave of the owner that is killed, the builder shall give slave for slave to the owner of the house.

Around 15 BC Vitruvius wrote De Architectura, a ten-volume treatise on architecture and construction which served as guidance on building projects in the Roman Empire. The books provide information about Roman building methods as well as the planning and design of structures. The books include sections on a wide range of topics such as town planning, architecture and civil engineering in general, building materials, civil and domestic buildings, water supply systems as well as fundamental mathematical and engineering knowledge and give advice on the use and construction of machines. In his books, Vitruvius advises the avoidance of lead in drinking water systems although there remain countries where this advice has not been heeded, as recently evidenced in the United States [10].

The next important series of books on building and architecture did not appear until 1452 when Alberti compiled and published De re aedificatoria (On the art of building) which is based on Vitruvius books with a critical review of contemporary influences from the Renaissance.

The Industrial Revolution in Britain coincided with a construction boom which called for regulations to cope with the many construction methods and available materials. Over a century later British Standards were introduced by the British Standard Institution (BSI) in 1901. The first national code for reinforced concrete structures was published in 1934. The requirements for a durable concrete construction were clearly laid out in cement and concrete standards as well as in codes of practice for concrete structures and county council by-laws. Such standards and codes have been revised, updated and, where appropriate, also withdrawn over the years. Innovations, such as calcium chloride-based set accelerators, high alumina cement (HAC) and super-sulphated cement, came in and out of standards as their benefits were recognized and limitations identified. 


\section{CEMENT}

\subsection{General}

Concrete and mortar are typically three-phase systems consisting of a binding material (cement), aggregates and water. The fine and coarse aggregates may comprise three quarters of the volume of concrete and their maximum size governs their classification into concrete or mortar. The latter typically has a maximum aggregate size of $4 \mathrm{~mm}$ whereas there is no limitation for concrete. Nowadays, concrete is more regularly a five-phase system because of the addition of additives and admixtures for property improvement and cost reduction.

Since the development of the highly successful Portland cement, several other types and variations have been patented. Ordinary Portland cement is the most common type of cement but is not suitable for all environmental conditions such as aggressive soils and solutions and can cause significant deterioration if used in an unsuitable environment. To reduce costs, more economical cements are also desirable along with fast hardening cements which could significantly reduce the time of construction.

Portland cement has been blended with slag and pozzolanic materials which also improved the durability. To resist aggressive environments, sulphate-resisting cements were developed such as super-sulphated cement and HAC, both of which can have problems with respect to durability and repair.

\subsection{Portland cement}

The chemical compounds of Portland cement were identified by Le Chatelier in 1882 . The largest compound is tricalcium silicate $\left(\mathrm{C}_{3} \mathrm{~S}=3 \mathrm{CaO} * \mathrm{SiO}_{2}\right)$ with over $50 \%$, followed by dicalcium silicate $\left(\mathrm{C}_{2} \mathrm{~S}=2 \mathrm{CaO} * \mathrm{SiO}_{2}\right)$ with less than $20 \%$, tricalcium aluminate $\left(\mathrm{C}_{3} \mathrm{~A}=3 \mathrm{CaO} * \mathrm{Al}_{2} \mathrm{O}_{3}\right)$ with less than $10 \%$ and tetracalcium aluminoferrite $\left(\mathrm{C}_{4} \mathrm{AF}=4 \mathrm{CaO} * \mathrm{Al}_{2} \mathrm{O}_{3} * \mathrm{Fe}_{2} \mathrm{O}_{3}\right)$ with less than $10 \%$. The $\mathrm{C}_{3} \mathrm{~S}$ and $\mathrm{C}_{2} \mathrm{~S}$ react with water to produce calcium-silicate-hydrate (CSH) phases which give the cementitious material its strength. The tricalcium aluminate phase $\left(\mathrm{C}_{3} \mathrm{~A}\right)$ requires gypsum to be present in the cement to prevent its immediate setting. After water is added, a so-called ettringite phase is produced on the surface of the $\mathrm{C}_{3} \mathrm{~A}$ grains which assists workability. Ettringite ideally forms during the initial stages but can also form at a later stage which may prove disruptive to the integrity of the concrete.

Portland cement-based materials have been widely used in the conservation of structures, for example to reinstate masonry mortar, replace deteriorated elements and fill voids and cavities to stabilize structures by grout injection. Such injections can address issues within the body of a structure or around its foundations.

Prior to the development of Portland cement, gypsum-based binders were widely used and the presence of such binders may not be obvious in cavities or other hidden areas [11]. The use of cementitious or lime grouts to inject such cavities may have detrimental effects due to the potential reaction with the original gypsum mortar in the presence of moisture. Gypsum contains sulphate which reacts with the aluminate phases of the mortar to form more voluminous sulphate compounds such as gypsum, monosulphate and ettringite. Gypsum forms through the reaction between sulphate ions and calcium hydroxide in the presence of moisture and is generally the first reaction product. It is however soluble and in presence of aluminate and/or carbonate the reaction will continue to form more complex and more voluminous sulphate compounds. Ettringite formation is associated with the commonest form of sulphate 
attack. The formation of ettringite in hardened grouts, mortars or concrete causes significant expansion due to a 6 -fold increase in volume of the reaction product. This can cause swelling, resulting in displacements and cracking. Vertical displacement may become a significant issue when cavities around foundations are injected. Thaumasite is similar to ettringite but forms at temperatures below $15^{\circ} \mathrm{C}$ with an optimum temperature of around $8^{\circ} \mathrm{C}$. The cement paste is converted into a mushy white mass starting at the surface and progressing inwards. Contrary to ettringite formation aluminate is not required but the strength-giving $\mathrm{CSH}$ phases are attacked.

The use of Portland cement-based repair mortars in historic buildings where lime was originally used may result in undesired effects. Lime and cement-based mortars are chemically compatible but the physical properties are largely different. Lime mortars are more porous, have a reduced strength and are more flexible. Lime mortar allows masonry to 'breathe', that is, there is a continuous cycle of balanced moisture circulation by absorption and evaporation through the mortar's porosity whereas cement mortars act as an impermeable waterproof barrier. Therefore repointing lime-based masonry with cement mortar results in the prevention of the necessary breathing trapping water within the masonry. Long-term exposure to moisture and saturation of lime mortar can affect the strength of the mortar and also the brickwork due to, for example, freeze-thaw action. Furthermore the strength of lime is significantly less than that of cement mortars. Joints are intended to weather preferentially to the brickwork and to accommodate a certain amount of movement. As a result of the higher strength of cement mortars the stresses are transferred to the brickwork leading to progressive cracking and erosion of the brickwork instead of the mortar joints. Some cement mortars may introduce salt into the masonry which may lead to crystallization on the surface and within the brickwork affecting strength and durability [12].

The mortars of historic structures are routinely analysed for their composition before repairs take place. The approach of 'like for like' has, however, not always been adopted or has been ignored and changes in the environmental conditions resulting in exposure to excessive moisture can initiate expansion. Cementitious injection grouts and repair mortars should only be used on historic structures after the completion of routine tests to be chemically and physically compatible with the original material. The visual appearance and aesthetic effects of the mortar should also be taken into account.

\subsection{Super-sulphated cement}

Super-sulphated cement was invented by Hans Kuehl [13] in 1908 in Germany. It is composed of granulated blastfurnace slag of $80-85 \%$, anhydrite of $10-15 \%$ and a small addition of up to $5 \%$ of Portland cement. The hydration products are ettringite and $\mathrm{CSH}$. The main advantage of this cement is that it can be manufactured almost without any additional burning processes and therefore many structures were built with this material during and after the war in Germany and Europe [14]. Due to its high resistance to sulphates and chemical conditions it was mainly used in the manufacture of concrete pipes for placement in contaminated, acidic or sulphate-containing ground, and in the construction of bridges over railway lines during the steam train era. The production ceased in Germany in the 1960s due to the lack of high alumina-containing blastfurnace slag because the composition of the slag changed as a result of using different raw materials. Nowadays slags are often less reactive than in former times. The cement has gained new popularity in recent years because of its low emission manufacturing process and the CEN Technical Committee TC 51 decided to designate a separate European standard EN 15743. 
Disadvantages of the cement are that carbonation results in a loss of strength whereas strength gain is observed in Portland cement-based concrete. Friable or powdery surfaces can also be encountered as a result of inappropriate curing leading to decomposition of the ettringite and an increase in porosity. Super-sulphated cement is beneficial in preventing alkaliaggregate reaction due to its low alkalinity which however reduces the resistance against corrosion of embedded steel [15].

Structures consisting of super-sulphated cement concrete may create a significant challenge to achieve long-lasting repairs. Due to the high sulphate content it is not possible to repair with Portland cement-based materials. Lime-based sealers are known to have been applied as standard practice in the past which however caused deterioration of the concrete. Furthermore lime from adjacent concrete elements based on Portland cement can also cause damage. The risk of sulphate attack at the interface between original substrate and repair mortar may cause significant degradation as a result of gypsum and ettringite formation in any Portland cement-based material.

The remediation of structures constructed using super-sulphated cement concrete should follow the 'like for like' principle and should be separated from adjacent Portland cementbased elements. Degradation due to inadequate curing, carbonation and exposure to lime from Portland cement mainly affects the outer skin of the structure, that is its appearance, but its structural integrity will not be affected.

\subsection{High alumina cement}

High alumina cement was developed by Jules Bied in France in 1908 to obtain an alternative to Portland cement with a higher resistance to sulphate attack. It consists of about $40 \%$ each of alumina and lime with around $15 \%$ of ferrous and ferric oxides, plus $5 \%$ silica. The resistance to sulphate attack is due to the absence of $\mathrm{Ca}(\mathrm{OH})_{2}$ in hydrated HAC and also due to the protective influence of the relatively inert alumina gel formed during hydration. $\mathrm{HAC}$ is not attacked by $\mathrm{CO}_{2}$ dissolved in pure water, and while it is not acid resisting, it can tolerate very dilute solutions of acids $(\mathrm{pH}>4)$ found in industrial effluents but not hydrochloric, hydrofluoric or nitric acids. Another positive feature of HAC is its very high rate of strength development. About $80 \%$ of its ultimate strength is reached in 24 hours, and even at 6 to 8 hours the concrete is strong enough for the side formwork to be struck and for the preparation for further concreting to take place. It is for this attribute that it became popular for the production of precast beams used in floor and roofing systems in the late 1960s and early 1970s (Fig. 3). However, engineers had already been warned in the code of practice CP114.100 - suspended concrete floor slabs and roofs from 1950 that 'High alumina cement may be unsuitable for use with certain aggregates... The user can only be guided by previous experience in determining whether it is suitable for use with such aggregates.'

Following a number of high-profile catastrophic failures that occurred in the early 1970s, the suitability of HAC concrete (HACC) for use in structural components has been of some considerable concern. The UK's Building Research Establishment (BRE) subsequently carried out a major investigation [16] and identified that HAC is subject to a process now known as conversion.

The conversion process involves a change in the mineralogy of the cement where the metastable calcium aluminate hydrates $\mathrm{CAH}_{10}$ and $\mathrm{C}_{2} \mathrm{AH}_{8}$ convert to the stable but less dense $\mathrm{C}_{3} \mathrm{AH}_{6}$ and water. This results in a more porous and friable structure of the strength-giving calcium aluminate hydrates and therefore the strength of the hydrated cement paste significantly reduces. The alkalinity is also affected by the conversion process and decreases. Also, 


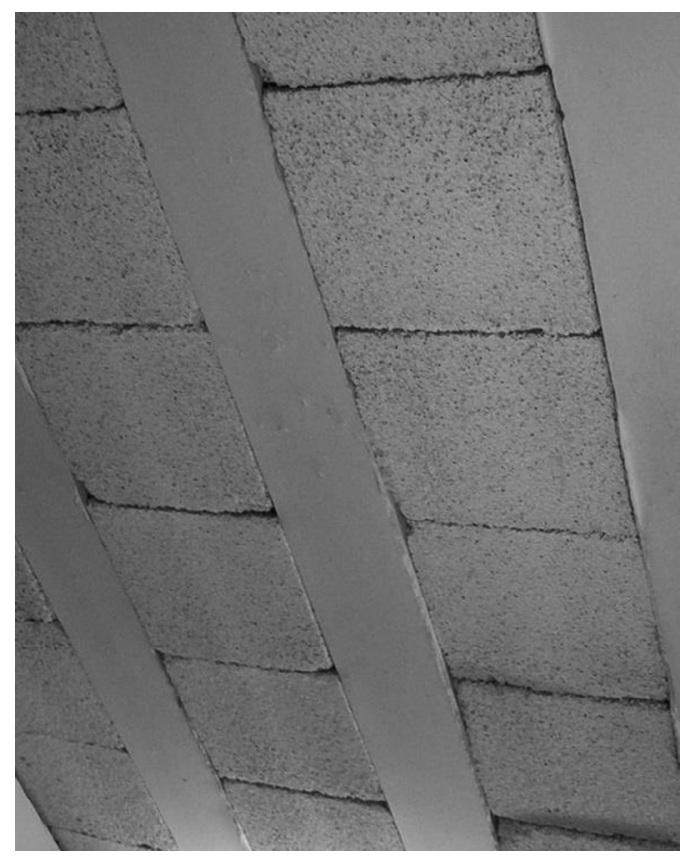

Figure 3: Typical HACC floor beams with block infill still in service in UK, subject to periodic inspection.

the increased porosity means the concrete is more susceptible to other forms of attack such as alkali, sulphate attack or carbonation which may result in reinforcement corrosion.

The effects of conversion on the strength of beams depend on the original strength and quality of concrete used. In some cases, the increase in porosity has been reported to allow moisture to react with unhydrated cement particles and produce an increase in strength. In other cases, significant strength reduction can take place.

Structures were built with HAC concrete until the mid-1970s in the UK and it was banned as a building material in 1976. Most countries on mainland Europe prohibited the use of HAC but France continues to use it to the present day.

Structures which still contain HACC elements are very unlikely to undergo catastrophic failure due to conversion. All conversion processes should have occurred during the previous 35 years since the ban was introduced. Deterioration may now be more related to corrosion or alkaline hydrolysis. Many public structures, which were constructed between the $1920 \mathrm{~s}$ and the mid-1970s, may contain HAC elements and can include schools, swimming pools and bridges. The type of cement should be identified before any restoration takes place and where appropriate strengthened or replaced.

\subsection{Asbestos cement}

Asbestos cement was developed in the United States in the early 1900s to form a more durable and fire-resistant material which was also easier to process, form and install [17]. At the time it had many economic benefits. 
Asbestos cement consists of Portland cement and is reinforced with asbestos fibres of which the content can vary from 10 to $75 \%$. This composite material gained great popularity and its production gradually increased between 1910 and 1940 and then more rapidly until 1960. It was mainly used for roofing, wall cladding, partition walls, panels, water pipes, sewage and underground drainage [18].

The asbestos fibres, of which crocidolite, amosite and chrysotile are the main types, are hazardous to people. Breathing in asbestos fibres can lead to asbestosis and lung cancer. The disease can take from 15 to 60 years to develop. Strict regulations have been widely introduced to deal with asbestos in buildings.

Asbestos cement used to be a very variable and much used material in the construction industry until the 1960s in Mainland Europe when it was phased out of production; however, it was not until 1998 that it was also finally banned from use in construction works in the UK. Asbestos is still used in many developing countries. In India the Asbestos Cement Products Manufacturers Association (ACPMA) [19] promotes asbestos-containing chrysotile fibres as a safe material to be used in cement products.

\section{CALCIUM CHLORIDE ADMIXTURE}

\subsection{General}

Admixtures have been used since the introduction of concrete. The Romans used blood, pig's fat and milk as additions to improve workability and durability. As a result of the high alkalinity of the concrete the blood and animal fat would change into soap forming small air voids during mixing [20]. Calcium chloride is an accelerating admixture that is added to concrete either to increase the rate of early strength development or reduce the setting time, particularly in cold weather. Such positive effects of calcium chloride on fresh concrete have been known of since 1873 [21] and the first patent is from 1885 [22]. This accelerator has been widely used in construction, although its negative effect on the durability of the reinforced concrete has led to the development of alternative non-corrosive accelerators.

\subsection{Beneficial short-term effects}

The corrosive effects of chlorides on metal have been known and studied since metallic materials were used in the construction of ships. In the case of concrete, calcium chloride was added to improve the properties of concrete in the short term, that is, during the construction phase. It was particularly useful to enable concreting in cold weather conditions and to speed up the construction process in general. The positive short-term effects for the industry dominated any long-term durability issues.

Extensive research was conducted into the effects of chloride admixtures, in particular by the Department of Scientific and Industrial Research in the UK after World War II. The Cement and Concrete Association published several advice notes for good concrete practice which also included the use of calcium chloride. In the report [14] of the Building Research Board from 1949 it is stated that 'the addition of various percentages of calcium chloride gave a marked increase in hydration at early ages, the difference between the control specimens and those containing calcium chloride becoming smaller after 21 days, and becoming insignificant at 90 days'. In respect to the corrosive effects the Board states that 'So far, the amount of corrosion is small, though there is a greater degree of corrosion with thin than with thick covers and more in those concretes containing calcium chloride than in those without.' 
In the 1955 advice notes [23] of the Cement and Concrete Association to practitioners for concreting in cold weather, several precautionary measures were recommended. The extension of curing time and the insulation of the concrete after placing was always recommended at low temperatures; however, there was the possibility to accelerate the hardening process instead. This could be done by (a) the use of an extra-rapid-hardening or rapid-hardening cement or (b) by using an accelerator. Finely ground, extra-rapid-hardening cement was generally preferred for cold weather work but if it was not possible to use it, an accelerator should be added. Calcium chloride was recommended as the most commonly used one. The usual recommended addition was a maximum of $2 \%$ calcium chloride by weight of cement. The type of salt was not specified but the flake form was generally preferred.

The association notes that 'Various proprietary accelerators, some based on calcium chloride, are on the market and should generally be used according to the maker's instructions. Some makers, however, have been known to recommend the use of large proportions of their accelerators in very cold weather and this is not good practice.'

In addition to the advice on the maximum allowable proportion it was stated that 'An accelerator should never be added to extra-rapid-hardening cement. Neither rapid-hardening nor extra-rapid-hardening cements nor accelerators are sufficient alone to protect concrete from frost, and the concrete must be insulated as well.'

As early as 1948 and 1957 in the Code of Practice (CP 114) for 'Structural use of reinforced concrete in buildings' it was understood that the use of calcium chloride may cause reinforcement corrosion and therefore advice notes were published by government bodies and cement manufacturers and a maximum proportion recommended. However, the calcium chloride-producing chemical industry suggested relating the maximum proportion to the air temperature as it is stated in an advice note by the Imperial Chemical Industries [24] (ICI) from 1958. Table 1 gives recommended amounts by ICI of calcium chloride to be added to the mix. These quantities were not rigidly fixed and may be varied to suit local conditions which could have caused higher proportions. The type of salt recommended was the flake form as it was most easily added directly to the aggregates and cement in the skip of the mixer.

ICI called calcium chloride 'a valuable addition to concrete for giving high early strength by accelerating the setting and hardening processes'. In its leaflet it explains the effects on the concrete properties and dismisses any negative aesthetic effects caused by efflorescence. The effects of calcium chloride on the reinforcing steel are also discussed and stated as:

Table 1: Recommended amounts of calcium chloride, ICI, 1958.

\begin{tabular}{|c|c|c|c|c|}
\hline \multirow[t]{2}{*}{ Air temperature } & \multicolumn{4}{|c|}{ Percentage weight by mass of cement } \\
\hline & $\% \mathrm{CaCl}_{2}$ & $\% \mathrm{Cl}^{-}$ & $\% \mathrm{CaCl}_{2}$ & $\% \mathrm{Cl}^{-}$ \\
\hline & \multicolumn{2}{|c|}{$\begin{array}{l}\text { Ordinary } \\
\text { Portland cement }\end{array}$} & \multicolumn{2}{|c|}{$\begin{array}{l}\text { Rapid-hardening } \\
\text { Portland cement }\end{array}$} \\
\hline$<32^{\circ} \mathrm{F}\left(<0^{\circ} \mathrm{C}\right)$ & $2.68-3.57$ & $1.71-2.28$ & $1.78-2.68$ & $1.14-1.71$ \\
\hline $32-40^{\circ} \mathrm{F}\left(0-4.4^{\circ} \mathrm{C}\right)$ & 2.68 & 1.71 & 1.34 & 0.86 \\
\hline $40-70^{\circ} \mathrm{F}\left(4.4-21.1^{\circ} \mathrm{C}\right)$ & 1.78 & 1.14 & 0.89 & 1.14 \\
\hline$>70^{\circ} \mathrm{F}\left(>21.1^{\circ} \mathrm{C}\right)$ & $0.89-1.34$ & $0.57-0.86$ & - & - \\
\hline
\end{tabular}


Calcium chloride, under ordinary conditions of curing, forms an insoluble compound with ingredients of the cement, and thus loses its identity and its corrosive nature. Years of experience and extensive practical trials have shown that there is negligible corrosion of the steel in normal in situ reinforced concrete or precast concrete cured at ordinary temperatures, when calcium chloride is used. Experiments continued over a number of years have indicated that such slight corrosion as occurs, appears in the initial stages and is not progressive. When there is insufficient cover or when the concrete is permeable, corrosion can take place with or without the use of calcium chloride.

At the present time some caution is advised in the case of prestressed concrete, in particular that made by systems in which the wet concrete comes in contact with the wires. The small diameter of these leaves a smaller margin for failure by corrosion and one or two failures have been reported which are at present unexplained. A number of possible contributory factors, probably in combination, call for investigation; one of these is the presence of calcium chloride. A programme of research to determine the facts about the use of calcium chloride is being carried out at the Building Research Station. The Cement and Concrete Association is also collaborating in these investigations.

The manufacturers of calcium chloride acknowledged the corrosive effects on prestressed concrete elements but completely neglected the effects on reinforcing steel and also increased the maximum allowable proportion up to $3.57 \%$ calcium chloride by mass of cement. It should be noted that the limit is very unclear as either the solid/pure or flake form of calcium chloride could be used. It was not explicitly specified until 1968 when it was stated in the Cement and Concrete Association leaflet [25] that 'The correct proportion to add is $1.5 \%$ of pure calcium chloride by weight of cement, or $2 \%$ of commercial flake calcium chloride which is $70-72 \%$ pure, the remainder being water and other harmless compounds.' Ramachandran [26] states that $2 \%$ of the flake form is equivalent to $1.5 \%$ of anhydrous calcium chloride but if $2 \%$ of the anhydrous salt was tolerated then $2.65 \%$ of the dihydrate may have been used.

In the Code of Practice (CP 110) for the structural use of concrete from 1972 it was stated that 'In concrete containing embedded metal calcium chloride must not be added in such proportion that the total from the admixture and the total from the aggregates exceeds $1.5 \%$ by weight of cement. Calcium chloride should never be used in prestressed concrete.'

\subsection{Detrimental long-term effects}

The confusing recommendations with respect to the maximum limit of calcium chloride to be added to the mix and the aim to build fast during all seasons must have contributed to the long-term durability issues of reinforced concrete constructed during this period. The statements with respect to corrosive effects give some warning of the potential problems but the real consequences were not properly addressed until much later.

Chlorides can be bound in solid compounds by the cement hydration products; however, the binding ability is limited and finite. The chloride content which can be bound in the hydrate phases depends on several parameters. The literature [27-29] suggests approximately $25-50 \%$ of total chlorides can be bound with a maximum threshold of $0.4 \%$ by mass of cement. The remaining chloride ions are freely available in the pore solution. Assuming that calcium chloride was added within its limits of $1.5 \%$ pure calcium chloride then the total internal chloride content of an element would be $1 \% \mathrm{Cl}^{-}$by mass of cement. $0.4 \%$ may be bound but there remains $0.6 \%$ free chloride available. 
The free chloride content may increase over time when the concrete carbonates. Carbonation causes a decrease of the normal concrete alkalinity from $\mathrm{pH} 12.5-13$ towards $\mathrm{pH} 9$ and during this process bound chlorides are released back into solution. If the carbonation front progresses to the depth of the reinforcement the protective layer on the steel destabilizes which may initiate corrosion in the presence of oxygen and moisture. The release of chlorides into the pore solution may exceed the critical chloride threshold and cause corrosion before the carbonation front reaches the reinforcement. The critical chloride threshold is approximately $0.5 \%$ chloride by mass of cement, at which point some corrosion is likely to occur. Corrosion of reinforcement causes the formation of voluminous reaction products which can cause spalling and delamination of the concrete cover.

The use of calcium chloride as an accelerator in the past may cause significant deterioration of reinforced concrete structures in the future. If no chlorides from external sources have already initiated corrosion then the relatively slow process of carbonation can be the trigger. The time until the carbonation front reaches the reinforcement depends on several parameters. These are mainly the depth of concrete cover and the permeability of the concrete and it could take 100 years or more for the problem to develop.

In EN 206 it is stated that the maximum chloride content of all concrete compounds should not exceed $0.4 \%$ by mass of cement and admixtures should be chloride free for concrete containing reinforcement or embedded steel. The maximum chloride content for prestressed concrete is $0.2 \%$ by mass of cement. Calcium chloride as an accelerator in reinforced concrete was effectively banned in the UK in 1977 when corrosion first started to be considered seriously.

The Code of Practice CP110 from 1972 was revised in 1977 when a major amendment was made in relation to the use of calcium chloride. 'Experience shows that corrosion of prestressing tendons, reinforcement and embedded metal usually results from the combination of factors including excess addition of calcium chloride ... departure from specified mix proportions, poor compaction, inadequate cover and poor detail design.' BS 8110:1985 clearly states that 'Calcium chloride and chloride-based admixtures should never be added in reinforced concrete, prestressed concrete and concrete containing embedded metal.'

\subsection{Remediation of chloride-contaminated concrete}

Chloride-contaminated concrete as a result of the use of calcium chloride can be identified by an even distribution of the chloride content which can be expected to be between 1 and $2 \%$ by mass of cement. Concrete that has been contaminated due to external sources can be identified on the chloride profile that decreases from the face of exposure. As stated in EN 206 the maximum chloride content should not exceed $0.4 \%$ by mass of cement because the risk of corrosion increases with increasing chloride content.

Electrochemical techniques such as cathodic protection or chloride extraction can be applied to protect concrete structures against ongoing corrosion. Reinforced concrete can be cathodically protected using various methods by means of an impressed current cathodic protection (ICCP) or galvanic (sacrificial) system. Both systems work by polarizing the reinforcement in an electrical circuit so the anodic, metal-dissolving mechanism is forced to take place at an installed anode. ICCP systems generally use inert long-life electrode such as mixed metal oxide-coated titanium. The reinforcement is polarized using an external DC power source. Galvanic systems use less noble metal electrodes, commonly zinc, aluminium or magnesium, which corrode preferentially to the steel and thereby provide the required protection. 
For heritage structures it is important that the original appearance is maintained which can be achieved by installing a cathodic protection system comprising of discrete anodes which for example can be installed from the inside of the building and lost behind wall finishes.

The application of CP can result in a number of potentially beneficial side effects. The ferrous component, being the cathode in a corrosion cell, generates hydroxyl ions which help maintain a passive oxide film on the surface of the steel and help protect it from further corrosion. In addition, because the cathode is negatively charged, ions such as chloride are repelled from the steel and attracted to the inert anodes.

While these processes occur naturally as a consequence of CP, they can also be optimized as remediation treatments in their own right. An optimized CP system can be applied temporarily in order to reduce chloride levels and then be removed. This means that the affected material can be treated in situ and potentially returned to its original condition and appearance. Commercially this technique is referred to as electrochemical chloride extraction (ECE), although in the past sometimes it has been confusingly referred to as 'desalination' [30].

The ECE system employs a temporary anode system held on the surface of the concrete within an electrolyte, either by means of tanks or in the form of a papier mâché poultice. The electrolyte is commonly calcium hydroxide solution as this prevents the generation of chlorine at the anode surface.

Realkalisation is another optimized CP system but not applicable for the remediation of chloride-contaminated concrete. Corrosion inhibitors can provide protection but only up to $1 \%$ chloride by mass of cement.

\section{SUMMARY}

History has taught us that not all human innovations prove successful in the long term. The development of construction methods and materials has been underway since the first settlements. The discovery of the pozzolanic properties of volcano ash led to a first boom of concrete construction but faltered after the fall of the Roman Empire. The demand for a plentiful and readily available building material and the invention of Portland cement led to a second concrete boom which continues to this day.

The only main constituent of concrete which can significantly alter the properties of concrete in the long term is the cementitious element. Admixtures can improve short-term properties which are relevant during construction. Water and aggregate are relatively fixed constituents. Therefore the focus has been on the cement and admixtures.

Portland cement is the most commonly used binder but not necessarily the most resistant and compatible one. The use of Portland cement-based grouts and mortars need to be carefully considered in the restoration of structures as the chemical reactions between the original mortars and the cement may take place. Different physical properties of materials also have a significant impact. 'Like for like' is the optimum restauration approach but if this is not feasible then the materials need to be chemically, physically and aesthetically compatible. This has not always been the case and the effects have or will appear.

Super-sulphated cement and HAC were developed to provide a higher resistance but both cements have caused problems and may be encountered in buildings constructed between 1910 and 1960. The super-sulphated cement is very durable; however, when reinstatement is necessary then it can create major problems if the wrong repair material is used.

High alumina cement has already caused several structural failures but it is suggested that the detrimental conversion process should now be completed in most structures. There is still the likelihood that HAC structures need to be strengthened. HAC elements are prone to further deterioration processes such as corrosion and improper repair may cause more problems. 
Asbestos used to be a very useful material to improve the concrete properties but it turned out to bring critical health problems to those handling it without proper protection.

The admixture calcium chloride has proved very useful to improve the properties of fresh concrete so that construction was possible throughout the whole year, even in very cold condition. This was a huge benefit in the short term but in the long term the negative effects, such as degradation due to corrosion, were much greater. Chloride-contaminated reinforced concrete structures can be repaired using electrochemical techniques such as cathodic protection and chloride extraction. Nowadays calcium chloride is effectively banned in most countries from use in concrete, along with asbestos and HAC.

\section{REFERENCES}

[1] Nabatacan History, available at http://nabataea.net/cement.html (accessed 21 March 2016).

[2] Morris, J. \& Sephton, S.S., The role of cement and concrete industry in developing countries. Proceeding of Concrete in the Service of Mankind: Concrete for Environment Protection and Enhancement, eds. R.K. Dhir, \& T.D. Dyer, CRC Press: London, pp. 29-41, 1996

[3] Schaeffer, R.E., Reinforced Concrete, Preliminary Design for Architects and Builders; Handout on Skyscrapers, McGraw-Hill Inc.: World Book Encyclopedia, 1992

[4] Moore, M., Great Wall of China's strength 'comes from sticky rice'. The Telegraph, 30 May 2010

[5] ASTM C618 - Standard Specification for Coal Fly Ash and Raw or Calcined Natural Pozzolan for Use in Concrete

[6] Bernstein, P.L., The Erie Canal: The waterway that shaped a great nation. 'Portrait of America' Volume 1, Part 10, eds. St. B. Oates, C.J. Errico, 10th ed., Wadsworth: Belmont, California, pp. 242-253, 2011

[7] Morgan, R.G. \& Morgan, J.E., The armature that made history: The boats of Joseph Louis Lambot. Proceedings of the 6th Internal Symposium on Ferrocement, Ferrocement, 6, pp. 11-34, 1998

[8] Encyclopædia Britannica, www.britannica.com/EBchecked/topic/389450/JosephMonier

[9] Legal History and Philosophy, available at http://www.commonlaw.com/home/legalhistory-and-philosophy/code-of-hammurabi (accessed 11 November 2015)

[10] United States Environmental Protection Agency, available at https://www.epa.gov/ your-drinking-water/basic-information-about-lead-drinking-water\#regs (accessed 21 March 2016)

[11] Stuermer, S., Injektionsschaummoertel fuer die Sanierung historischen Mauerwerks unter besonderer Beruecksichtigung bauschaedlicher Salze, Dissertation, BauhausUniversity Weimar, 1997

[12] Mitchell, D. \& Torney, C., The Use of Lime and Cement in Traditional Buildings, Information for Historic Building Owners, Historic Scotland, Longmore House, Salisbury Place, Edinburgh, April 2015

[13] Kuehl, H., Verfahren zur Herstellung von Zement aus Hochofenschlacke. DRP Nr. 137 777, 23.12.1908.

[14] Department of Scientific and Industrial Research, Report of the Building Research Board, Watford, 1949.

[15] Concrete Society Technical Guide No.9 - Guidance on the Assessment of Concrete Bridges, Camberley, UK, 2007. 
[16] BRE Digest 392, Assessment of Existing High Alumina Cement Concrete Construction in the UK, BRE, UK, 1994.

[17] Hornbostel, C., Construction Materials: Types, Uses and Applications, John Wiley \& Sons, New York, 1978

[18] HSE, Working with Asbestos Cement. HSG189/2, 1999.

[19] The Asbestos Cement Products Manufacturers Association (ACPMA), available at www.acpma.com/fact-asbestos.html (accessed 11 November 2015).

[20] Aitcin, P.C., Cements of yesterday and today: Concrete of tomorrow. Cement and Concrete Research, 30(9), pp. 1349-1359, 2000. DOI: 10.1016/s0008-8846(00)00365-3.

[21] Kuhl, H. \& Ullrich, E., Chloride cracking. Zement, 14, pp. 859-861, 880-882, 898901, 917, 1925.

[22] Millar, W. \& Nichols, C.F., Improvements in means of accelerating the setting and hardening of cements. Brit. Patent No. 2, 886, March 4, London, England, 1885.

[23] Cement and Concrete Association, Concreting in Cold Weather-Man on the Job Leaflet, London, 1955

[24] Imperial Chemical Industries Ltd., Calcium Chloride - In Concrete Making, 2nd ed., Mears \& Caldwell Ltd.: London, 1958.

[25] Cement and Concrete Association, Concreting in Cold Weather-Man on the Job Leaflet, London, 1968

[26] Ramachandran, V.S., Calcium chloride in concrete - applications and ambiguities. Canadian Journal of Civil Engineering, 5(2), pp. 213-221, 1978. DOI: 10.1139/178-025

[27] Richartz, W., Die Bindung von Chlorid bei der Zementerhaertung. Zement-Kalk-Gips, 22, pp. 447-456, 1969.

[28] Arya, C., Buenfeld, N.R. \& Newman, J.B., Factors influencing chloride-binding in concrete. Cement \& Concrete Research, 20, pp. 291-300, 1990. DOI: 10.1016/00088846(90)90083-A.

[29] Breit, W., Critical Corrosion Inducing Chloride Content - State of the Art and New Investigation Results. Concrete Technology Report. VDZ., Duesseldorf, Germany, 2000.

[30] McFarland B, Electrochemical Repair Using Realkalisation and Chloride Extraction Techniques. Concrete Repair Association Guidance Note, Bordon, UK, 1999. 